\title{
Development of visual-motor integration scale for the Korean old people
}

\author{
Mi-Sook Park', Yong-Kyung Park'2, Eunhwi Kim², Hong Kim, \\ 'Department of Health and Welfare for Elderly, Daegu Haany University, Gyeongsan, Korea \\ ${ }^{2}$ Department of Nursing, Kyungil University, Gyeongsan, Korea \\ ${ }^{3}$ Department of Korean Sports Medicine, Daegu Haany University, Gyeongsan, Korea
}

Effective methods to detect old people cognitive decline in early stages are needed in Korea, which is the fastest aging country in the world. This study aimed to develop a brief cognitive function measurement, $\mathrm{Vi}$ sual-Motor Integration Scale for the Korean elderly (VMIS-KE). In this methodological research, 16 preliminary items on visual-motor integration for the old people were chosen after literature review and expert validation. One hundred eighty participants aged $20-79$ years were recruited to verify the validity and reliability of this measurement from community sources in Daegu city. The collected data were analyzed by exploratory factor analysis and confirmative factor analysis using SPSS and AMOS 18.0 program. The three factors (figure cognition, memory, and spatial cognition) with 12 items were finally extracted. Goodness of the fit was confirmed through confirmatory factor analysis. The Cronbach $\alpha$ was 0.867 . The scores of overall VMIS-KE and every subcategory significantly decreased with age, especially in the 70s. VMIS-KE is the first valid and reliable measurement to assess cognitive decline of the Korean old people through visual motor integration, and can easily and quickly detect high-risk groups of dementia regardless of their educational level.

Keywords: Visual-Motor Integration, Korean, Old people, Visual perception, Cognition

\section{INTRODUCTION}

In Korea, the old people aged 65 or older exceeded $15.7 \%$ of the total population in 2020, and it is predicted to continue to increase in the future and reach $20.3 \%$ in 2025, making Korea a super-aged society (Statistics Korea, 2021). Age is a major risk factor for cognitive decline and dementia, all of which have high associated costs of diagnosis, treatment, and care. Therefore, the aging of the population raises serious concerns about the fiscal integrity of health care systems (Fernández Martínez et al., 2008; Shlisky et al., 2017). The likelihood of progression from mild cognitive impairment to any form of dementia has been suggested to occur at a rate 3 to 5 times higher than those with normal cognition (Campbell et al., 2013). In order to prevent dementia, there is a need for a practical plan for early screening and management of high-risk groups for dementia by predicting cognitive decline along with chronic disease.

Association between visual impairment and poor cognitive functioning has been reported by several studies (Clemons et al., 2006; Harrabi et al., 2015; Spierer et al., 2016). Visual function is divided into visual perception and visual-motor integration (VMI), and many cognitive screening tests, such as the Blessed Information-Memory-Concentration Test (Blessed et al., 1968), Short Portable Mental Status Questionnaire (Pfeiffer, 1975), Dementia Rating Scale (Knox et al., 2003), and Mini-Mental State Examination (MMSE) (Folstein et al., 1975), were developed with an emphasis on it. Among them, MMSE has been most frequently used to screen the old people dementia in the world (Lancu and Olmer, 2006). However, MMSE has been reported to "false-negative" in people with mild cognitive decline (Nelson et al., 1986) and MMSE has some limits of detection of early dementia with mild cognitive impairment (Folstein et al., 1975).

First of all, as it is focused on the language domain, it is insuffi-

${ }^{*}$ Corresponding author: Hong Kim (iD https://orcid.org/0000-0001-8740-3600 Department of Korean Sports Medicine, Daegu Haany University, 1 Haanydae-ro, Gyeongsan 38610, Korea

Email: joshua@dhu.ac.kr

Received: June 1, 2021 / Accepted: June 29, 2021
This is an Open Access article distributed under the terms of the Creative Commons Attribution Non-Commercial License (https://creativecommons.org/licenses/by-nc/4.0/) which permits unrestricted non-commercial use, distribution, and reproduction in any medium, provided the original work is properly cited. 
cient to evaluate visual cognitive function. In addition to that, it has to be considered age and gender in the interpretations of the test results (Tombaugh and Mclntyre, 1992). Therefore, it is necessary to modify or supplement MMSE or to develop a new cognitive function measurement suitable for the old people to more accurately judge the old people dementia.

Visual-motor function is an important cross-modal ability that involves the integration of visual function and perception, eye-hand coordination, fine motor skills, and visual-motor integration (Bolk et al., 2018). As a result of previous studies, VMI has been suggested as an effective instrument for measuring intellectual ability, language ability, various brain abnormalities (Belmont and Belmont, 1980). In addition to that, it has been suggested for cognitive function of the old people (Hall et al., 1996) and the old people diabetic patients (Yun et al., 2013). However, few studies have been applied VMI to detect cognitive function of the old people so far (Yun et al., 2013). This is because there is currently no proven VMI evaluation tool available in the field although it is effective in predicting changes in cognitive function of the old people.

Therefore, this study attempted to develop a VMI scale that measures changes in cognitive function of the old people. In particular, by developing a simple cognitive function measurement tool that is suitable for the Korean old people and can be applied immediately in the clinical field, it is intended to help prevent and manage dementia through early detection of the old people at high risk of dementia.

\section{MATERIALS AND METHODS}

\section{Design}

This is a methodological study to develop a scale to measure VMI for Korean old people and verify its reliability and validity.

\section{Development of VMI Scale for the Korean elderly (VMIS-KE)}

Visual perception, motor coordination, and executive function were probably associated with the VMI development (Fang et al., 2017). Firstly, visual perception was identified as the ability to receive, recognize, analyze, and elaborate the visual stimulus from objects and events. Secondly, motor coordination was related to the rebuilding of the representation in mind during the visual motor integration process. Fine motor coordination was proposed to interact with the VMI development. Thirdly, executive function contained three subcomponents that were inhibitory control, working memory, and cognitive flexibility.

Therefore, in this study, visual motor integration was defined as an ability to accurately recognize and complete shape of figure in drawing based on eye-hand coordination, to recognize and express exact location of space, and to exactly memorize figure and space.

Based on the literature review, the initial items of VMI were composed with coordination and speed of eye-hand, consistency and accuracy of space and figure, and memory. Every item was developed based on drawing ability to be measured in an integrated form of visual perception and motor function, and was simple and easy enough for the old people to follow. Considering that the target population was the old people, the number of items was organized less than 30 questions and less than 10 min not too long.

The content validity of the initial items had evaluated by four experts including one doctor of the medicine, two doctors of the nursing, and one doctor of the statistics. They were revised and supplemented with reference to opinions of the experts on appropriateness of the subconcepts for measuring visual motor integration and applicability to the subjects.

The preliminary items were composed of two categories and six subgroups according to spatial and figure consistency perception. The category related to spatial perception was divided into two subgroups: eye-hand coordination (3 items) and position (3 items), and the category related to figure consistency perception was divided into four subgroups: accuracy ( 3 items), speed (1 item), memory (3 items), and closure ( 3 items). The preliminary VMIS-KE was composed of a total of 16 items. It took about $10 \mathrm{~min}$ for the subjects to complete the questionnaires of VMIS-KE, and it was confirmed whether there were too difficult or ambiguous items in the preliminary study. As selecting and developing the items, the content and composition validity were refined through literature reviews and expert consultation, the reliability was evaluated through the statistical analysis, and the content and number of items in the developed questionnaire were finally decided.

In VMIS-KE, VMI was classified into three categories through the statistical test, factor analysis, and they were named as figure cognition, memory, and spatial cognition. Twelve items were reclassified into these 3 subcategories according to the concept and definition. Figure cognition means the ability to accurately recognize the shape of a given figure through visual perception and draw along or complete it, and was composed of a total of 5 items. Memory means the ability to recall and draw the figure remembered through visual perception or to respond appropriately while remembering the condition, and was composed of a total of 4 items. Spatial cognition means the ability to draw lines or figures in a designated space by eye-hand coordination through visual recognition, and was composed of a total of 3 items. 


\section{Subjects and data collection}

The subjects of this study were adults 20 years old or older, who understand the purpose of this study and agree to participate, who can communicate and do not have a neurological psychiatric history, who are not currently receiving treatment under the diagnosis of a doctor related to cognitive impairment and who do not have visual impairment. Data were collected from community sources such as public health care centers, senior centers, and universities located in Daegu city from July 1 to July 26, 2013 after the permission of the institutions. Data collection was conducted by trained research assistants with a one-by-one interview method using the VMIS-KE. Research assistants received prior training on basic understanding of the VMIS-KE and detailed instructions about how to use it, and the training was repeated until the degree of agreement between them reached Kappa index of 0.90 or higher. To verify validity of a scale, more than 5 times the number of items for exploratory factor analysis are required. In this study, in order to investigate the age-specific differences of VMIS-KE, data were collected from 30 subjects for each age group from 20s to 70s based on 10 years, and finally, 180 subjects were analyzed.

\section{Verification of validity and reliability}

The validity and reliability of VMIS-KE were testified as the following procedures. The collected data were analyzed using IBM SPSS ver. 18.0 (IBM Co., Armonk, NY, USA). First, descriptive statistics, including frequency, percentage, mean and standard deviation, were conducted to understand general characteristics of the subjects. The validity was verified by exploratory factor analysis, convergence validity, discriminant validity, and confirmatory factor analysis. Principal component analysis was used for exploratory factor analysis using Eigen value of 1.0 or higher and Vari- max rotation method, and Kaiser-Mayer-Olkin (KMO) scale and Bartlett's sphericity test were conducted to determine the suitability of factor analysis. In confirmatory factor analysis, fit indices were evaluated by $\chi^{2}$ statistics and $P$-value, root mean squared residual (RMR), root mean squared error of approximation (RMSEA), Turker Lewis index (TLI), and comparative fit index (CFI). The reliability was verified by Cronbach alpha, which is an internal consistency reliability coefficient. One-way variance analysis was implemented to confirm the difference by age group and the Scheffe posttest was done additionally if there was statistical significance.

\section{Ethical considerations}

The purpose and procedure, and the risks and benefits of this study were explained to the subjects. It was noticed that collected data were used only for the purpose of the study and withdrawn of participation can be done at any time. Every subject participated voluntarily with informed consent.

\section{RESULTS}

\section{Demographic characteristics of the participants}

The subjects of this study were 30 for each age group from 20 s to 70s and the proportion of women in all age groups was more than half (50\%-93.3\%). Body mass index by each age group was in the normal range of 21.72 to $23.40 \mathrm{~kg} / \mathrm{m}^{2}$ and there was no significant difference according to age ( $t=2.05, P=0.074)$. In terms of memory measured by MMSE, the 20s had the highest score with 14.43 points, and the 70s had the lowest score with 10.13 points, and there were significant differences according to age group $(t=17.06, P<0.001)$ (Table 1$)$.

Table 1. Characteristics of the participants by age groups $(N=180)$

\begin{tabular}{|c|c|c|c|c|c|c|c|c|}
\hline \multirow{2}{*}{ Classification } & \multicolumn{6}{|c|}{ Age group } & \multirow{2}{*}{$\operatorname{tor} \chi^{2}$} & \multirow{2}{*}{$P$-value } \\
\hline & 20 's & 30 's & 40 's & 50 's & 60's & 70's & & \\
\hline Number (\%) & $30(16.7)$ & $30(16.7)$ & $30(16.7)$ & $30(16.7)$ & $30(16.7)$ & $30(16.7)$ & & \\
\hline Age (yr) & $24.17 \pm 2.97$ & $33.43 \pm 2.79$ & $44.90 \pm 2.82$ & $54.00 \pm 3.38$ & $66.83 \pm 1.56$ & $75.20 \pm 3.89$ & $1,287.36$ & $<0.001$ \\
\hline Gender & & & & & & & $17.38^{\dagger}$ & $(0.003)$ \\
\hline Male & $15(50.0)$ & $12(40.0)$ & $2(6.7)$ & $6(20.0)$ & $8(26.7)$ & $8(26.7)$ & & \\
\hline Female & $15(50.0)$ & $18(60.0)$ & 28 (93.3) & $24(80.0)$ & $22(73.3)$ & $22(73.3)$ & & \\
\hline Height (cm) & $168.76 \pm 7.48$ & $167.47 \pm 6.75$ & $162.85 \pm 5.86$ & $161.53 \pm 7.22$ & $157.60 \pm 8.05$ & $157.15 \pm 8.61$ & 12.64 & $<0.001$ \\
\hline Weight (kg) & $64.38 \pm 11.16$ & $66.90 \pm 13.56$ & $57.77 \pm 10.64$ & $60.23 \pm 9.46$ & $58.75 \pm 6.73$ & $57.85 \pm 8.75$ & 4.04 & 0.002 \\
\hline Body mass index $\left(\mathrm{kg} / \mathrm{m}^{2}\right)$ & $22.46 \pm 2.60$ & $23.77 \pm 4.12$ & $21.72 \pm 3.08$ & $23.03 \pm 2.85$ & $23.66 \pm 2.21$ & $23.40 \pm 2.76$ & 2.05 & 0.074 \\
\hline Memory $^{\ddagger}$ & $14.43 \pm 0.86$ & $13.57 \pm 1.59$ & $14.10 \pm 1.12$ & $12.50 \pm 2.78$ & $11.43 \pm 2.69$ & $10.13 \pm 3.16$ & 17.06 & $<0.001$ \\
\hline
\end{tabular}

Values are presented as number (\%) or mean \pm standard deviation.

${ }^{\dagger}$ Fisher exact test. ${ }^{\ddagger}$ Memory measured by Mini-Mental State Examination. 


\section{Item analysis}

As a result of measuring mean and standard deviation, skewness and kurtosis, and correlation coefficient between individual and all questions to evaluate the validity of each question, the mean score of each question was 1.79 to 2.90 , the skewness was -4.976

Table 2. Results of item analysis ( $\mathrm{N}=180)$

\begin{tabular}{ccccc}
\hline Item & Mean \pm SD & Skewness & Kurtosis & Item-total correlation $(r)$ \\
\hline 1 & $2.69 \pm 0.702$ & -2.532 & 6.005 & 0.612 \\
2 & $2.34 \pm 0.947$ & -1.378 & 0.842 & 0.611 \\
3 & $1.79 \pm 1.092$ & -0.416 & -1.133 & 0.683 \\
4 & $2.90 \pm 0.437$ & -4.976 & 26.148 & 0.519 \\
5 & $2.66 \pm 0.735$ & -2.261 & 4.478 & 0.437 \\
6 & $2.32 \pm 1.087$ & -1.279 & 0.044 & 0.715 \\
7 & $2.03 \pm 0.642$ & -0.286 & 0.324 & 0.608 \\
8 & $1.82 \pm 0.758$ & -0.301 & -0.135 & 0.751 \\
9 & $1.97 \pm 0.794$ & -0.560 & 0.073 & 0.654 \\
10 & $2.63 \pm 0.724$ & -1.905 & 2.659 & 0.627 \\
11 & $2.86 \pm 0.383$ & -2.625 & 6.507 & 0.294 \\
12 & $2.37 \pm 0.985$ & -1.500 & 1.037 & 0.551 \\
13 & $1.94 \pm 1.206$ & -0.732 & -1.064 & 0.648 \\
14 & $1.84 \pm 0.659$ & -0.180 & 0.049 & 0.514 \\
15 & $1.80 \pm 0.688$ & 0.075 & -0.507 & 0.531 \\
16 & $2.24 \pm 1.146$ & -1.189 & -0.231 & 0.756 \\
\hline
\end{tabular}

$\mathrm{SD}$, standard deviation. to 0.075 , and the kurtosis was 1.133 to 26.148 , and the correlation coefficient was 0.294 to 0.756 . In the case of $1,4,5,11$ of the total items, the absolute value of skewness and kurtosis exceeded 2, and thus the distribution was not normally distributed. In addition to that, the correlation coefficient of Item 11 was so less than 0.30 that it was not suitable for factor analysis. Therefore, item 1, 4, 5, and 11 that were considered inappropriate were deleted (Table 2).

\section{Exploratory factor analysis}

Exploratory factor analysis was conducted for a total of 12 items whose relevance were confirmed as a result of the item analysis. The $\mathrm{KMO}$ scale was 0.886 , and the result of Bartlett's sphericity test was $\chi^{2}=851.38, P<0.001$, which satisfied the requirements for exploratory factor analysis. As a result of conducting exploratory factor analysis based on eigen value 1 or more using principal components analysis and Varimax rotation method, three factors were extracted from 12 items. The three factors accounted for $63.9 \%$ of the total variations, and every item met the criteria of more than 0.30 commonality and more than 0.40 factor loading (Table 3).

The three factors extracted from exploratory factor analysis were respectively named from figure cognition, memory, and spatial cognition. Factor 1 was figure cognition including 5 items corresponding to accurately recognize and follow the shape (item 7, 8,

Table 3. Factor analysis and reliability on Visual-Motor Integration scale for Korean elderly ( $N=180$ )

\begin{tabular}{|c|c|c|c|c|c|c|c|c|c|}
\hline \multirow{2}{*}{ Factor } & \multirow{2}{*}{ Item } & \multirow{2}{*}{ Mean \pm SD } & \multicolumn{3}{|c|}{ Factor loading } & \multirow{2}{*}{ Communality } & \multirow{2}{*}{$\begin{array}{l}\text { Corrected item to } \\
\text { total correlation }\end{array}$} & \multirow{2}{*}{$\begin{array}{l}\alpha \text { if item } \\
\text { deleted }\end{array}$} & \multirow{2}{*}{ Cronbach $\alpha$} \\
\hline & & & Factor 1 & Factor 2 & Factor 3 & & & & \\
\hline \multirow[t]{5}{*}{ Factor 1} & 7 & $2.03 \pm 0.62$ & 0.796 & 0.236 & 0.064 & 0.693 & 0.560 & 0.858 & 0.834 \\
\hline & 14 & $1.84 \pm 0.66$ & 0.789 & 0.101 & 0.022 & 0.633 & 0.452 & 0.863 & \\
\hline & 8 & $1.82 \pm 0.76$ & 0.713 & 0.352 & 0.291 & 0.717 & 0.713 & 0.849 & \\
\hline & 15 & $1.80 \pm 0.69$ & 0.700 & 0.014 & 0.292 & 0.576 & 0.486 & 0.861 & \\
\hline & 9 & $1.97 \pm 0.79$ & 0.607 & 0.295 & 0.291 & 0.540 & 0.603 & 0.854 & \\
\hline \multirow[t]{4}{*}{ Factor 2} & 13 & $1.94 \pm 1.21$ & -0.016 & 0.804 & 0.246 & 0.707 & 0.522 & 0.861 & 0.726 \\
\hline & 10 & $2.63 \pm 0.72$ & 0.240 & 0.743 & 0.017 & 0.610 & 0.530 & 0.859 & \\
\hline & 12 & $2.37 \pm 0.96$ & 0.201 & 0.632 & 0.048 & 0.443 & 0.449 & 0.864 & \\
\hline & 6 & $2.32 \pm 1.09$ & 0.244 & 0.617 & 0.338 & 0.555 & 0.619 & 0.852 & \\
\hline \multirow[t]{3}{*}{ Factor 3} & 2 & $2.34 \pm 0.95$ & 0.102 & 0.133 & 0.893 & 0.825 & 0.520 & 0.859 & 0.772 \\
\hline & 3 & $1.79 \pm 1.09$ & 0.378 & 0.166 & 0.719 & 0.687 & 0.609 & 0.853 & \\
\hline & 16 & $2.24 \pm 1.15$ & 0.193 & 0.555 & 0.581 & 0.682 & 0.687 & 0.847 & \\
\hline Eigen value & & & 2.971 & 2.608 & 2.088 & & & & \\
\hline Explained variance (\%) & & & 24.761 & 21.733 & 17.397 & & & & \\
\hline Cumulative variance (\%) & & & 24.761 & 46.494 & 63.890 & & & & \\
\hline
\end{tabular}

Factor 1, figure cognition; Factor 2, memory; Factor 3, spatial cognition; SD, standard deviation. Kaiser-Meyer-Olkin $=0.886$, Bartlett's sphericity $\chi^{2}=851.38(P<0.001)$.

Cronbach $\alpha 12$ item total $=0.867$. 
9) or complete (item 14, 15), and the explanatory power was $24.8 \%$. Factor 2 was memory including 4 items corresponding to draw the memorized figure (item 12,13), quickly respond and draw a connection line with remembering the given condition (item 10), or remember the location and mark it in the same place (item 6), and the explanatory power was $21.7 \%$. Factor 3 was spatial cognition including 3 items corresponding to draw lines (item 2,3) or figures (item 16) in a given space by eye-hand coordination, and the explanatory power was $17.4 \%$ (Table 3 ).

\section{Verification of convergence and discriminant validity}

As a result of the construct reliability (CR) value, which is the conceptual reliability of each sub-factor, it was 0.74 to 0.91 , more than the standard of 0.70 , and the convergence validity was verified. In order to verify the discriminant validity by confirming the low correlation and independence between the latent variables, the square values of the correlation coefficient between all latent variables and the average variance extracted (AVE) values were compared one another. The squared values of all latent variables were smaller than AVE, and the discriminant validity was verified (Table 4).

\section{Confirmatory factor analysis}

The confirmatory factor analysis used with a model consisting

Table 4. Confirmatory factor analysis on Visual-Motor Integration scale for Korean elderly $(\mathrm{N}=180)$

\begin{tabular}{|c|c|c|c|c|c|c|c|c|}
\hline \multirow[b]{2}{*}{ Factor } & \multirow[b]{2}{*}{ Item } & \multirow{2}{*}{$\begin{array}{l}\text { Standardized } \\
\text { estimate }(\beta)\end{array}$} & \multirow{2}{*}{$\begin{array}{c}\text { Standardized } \\
\text { measurement } \\
\text { error }\end{array}$} & \multicolumn{3}{|c|}{ Factor } & \multirow[b]{2}{*}{ CR } & \multirow[b]{2}{*}{ AVE } \\
\hline & & & & $1(r)$ & $2(r)$ & $3(r)$ & & \\
\hline \multirow[t]{5}{*}{ Factor 1} & 7 & 0.745 & 0.183 & 1 & - & - & 0.91 & 0.67 \\
\hline & 14 & 0.622 & 0.264 & & & & & \\
\hline & 8 & 0.861 & 0.148 & & & & & \\
\hline & 15 & 0.617 & 0.292 & & & & & \\
\hline & 9 & 0.685 & 0.333 & & & & & \\
\hline \multirow[t]{4}{*}{ Factor 2} & 13 & 0.707 & 0.724 & 0.644 & 1 & - & 0.74 & 0.42 \\
\hline & 10 & 0.632 & 0.313 & & & & & \\
\hline & 12 & 0.511 & 0.713 & & & & & \\
\hline & 6 & 0.726 & 0.555 & & & & & \\
\hline \multirow[t]{3}{*}{ Factor 3} & 2 & 0.685 & 0.474 & 0.700 & 0.764 & 1 & 0.75 & 0.50 \\
\hline & 3 & 0.723 & 0.566 & & & & & \\
\hline & 16 & 0.771 & 0.530 & & & & & \\
\hline
\end{tabular}

Factor 1, figure cognition; Factor 2, memory; Factor 3, spatial cognition; CR, construct reliability; AVE, average variance extracted; df, degrees of freedom; RMR, root mean squared residual; RMSEA, root mean squared error of approximation; TLI, Turker Lewis index; CFI, comparative fit index.

Model fitness: $\chi^{2}=105.42(P<0.001)$, degrees of freedom $=51$. RMR $=0.055$, RM$\mathrm{SEA}=0.077, \mathrm{TLI}=0.913, \mathrm{CFI}=0.933$. of 3 subfactors and 12 items. The suitability of the model fit was $\chi^{2}=105.42(P<0.001)$, degrees of freedom $=51$, RMR 0.055, RMSEA 0.077, TLI 0.913, and CFI 0.933, therefore, all fit indices were good (Table 4).

\section{Reliability verification of VMIS-KE}

As the result of the reliability verification, the correlation between individual items and the total score was 0.452 to 0.713 , which was higher than 0.30 for all items, and no items had a confidence coefficient greater than the total confidence coefficient when it was deleted. The Cronbach $\alpha$ of factor $1=0.834$, the Cronbach $\alpha$ of factor $2=0.725$, the Cronbach $\alpha$ of factor $3=0.772$, the Cronbach $\alpha$ of total VMIS-KE $=0.867$, every confidence coefficient was over 0.60 , and the internal consistency of the VMIS-KE was sufficiently high (Table 3).

\section{Differences of VMIS-KE by age and correlations with MMSE}

As a result of verifying the difference in VMIS-KE scores according to age group from 20s to 70s, VMIS-KE showed significant differences according to age $(F=40.93, P<0.001)$. The $20 \mathrm{~s}$ scored the highest with 29.57, the 60s scored 24.23, and the 70 s scored the lowest with 14.37. The post boc analysis showed that the 60 s was significantly lower than the 20 s and 30 s, and the 70 s was significantly lower than the 60s. In all subfactors, there were also significant differences according to age $(F=14.21-53.23$, $P<0.001)$. In the case of the factor 1 , figure cognitive ability, the 30 s scored 11.40 , significantly higher than 9.27 of the 60 s, and

Table 5. Mean differences of Visual-Motor Integration scale for Korean elderly (VMIS-KE) between each age groups, and correlations with Mini-Mental State Examination $(\mathrm{N}=180)$

\begin{tabular}{|c|c|c|c|c|}
\hline \multirow{2}{*}{$\begin{array}{l}\text { Age } \\
\text { group }\end{array}$} & VMIS-KE & Factor 1 & Factor 2 & Factor 3 \\
\hline & $0.794(<0.001)^{\dagger}$ & $0.442(<0.001)^{\dagger}$ & $0.947(<0.001)^{\dagger}$ & $0.500(<0.001)^{\dagger}$ \\
\hline Total & $25.11 \pm 7.01$ & $9.47 \pm 2.75$ & $9.26 \pm 3.01$ & $6.38 \pm 2.65$ \\
\hline 20 's & $29.57 \pm 3.26^{a}$ & $10.20 \pm 2.50^{a, b}$ & $11.43 \pm 0.82^{a}$ & $7.93 \pm 1.26^{\mathrm{a}}$ \\
\hline 30 's & $29.17 \pm 3.53^{\mathrm{a}}$ & $11.40 \pm 2.39^{\mathrm{a}}$ & $10.57 \pm 1.48^{a, b}$ & $7.20 \pm 1.88^{a}$ \\
\hline 40 's & $27.33 \pm 4.19^{a, b}$ & $9.17 \pm 2.32^{b}$ & $10.83 \pm 1.46^{a, b}$ & $7.33 \pm 1.95^{\mathrm{a}}$ \\
\hline 50 's & $26.00 \pm 6.37^{a, b}$ & $10.17 \pm 2.70^{a, b}$ & $8.80 \pm 3.20^{\mathrm{b}, \mathrm{c}}$ & $7.03 \pm 1.79^{a}$ \\
\hline 60 's & $24.23 \pm 5.74^{b}$ & $9.27 \pm 2.18^{b}$ & $8.03 \pm 2.98^{c}$ & $6.93 \pm 1.76^{a}$ \\
\hline 70's & $14.37 \pm 5.01^{c}$ & $6.60 \pm 1.96^{c}$ & $5.90 \pm 3.03^{d}$ & $1.87 \pm 1.43^{b}$ \\
\hline$F(P)$ & $\begin{array}{c}40.93(<0.001) \\
a>b>c\end{array}$ & $\begin{array}{c}14.21(<0.001) \\
a>b>c\end{array}$ & $\begin{array}{c}23.70(<0.001) \\
a>b>c>d\end{array}$ & $\begin{array}{c}52.23(<0.001) \\
a>b\end{array}$ \\
\hline
\end{tabular}

Values are presented as mean \pm standard deviation.

Factor 1, figure cognition; Factor 2, memory; Factor 3, spatial cognition; SD, standard deviation. a, b, c, d, different letters (a-d) denote statistically significant different subgroup by Scheffe post hoc $(P<0.05)$.

${ }^{\dagger}$ Correlation with Mini-Mental State Examination $(r / P)$. 
the 70s scored 6.60, significantly lower than the 60s'. In the case of factor 2 , memory ability, the 20 s scored 11.43 , significantly higher than 8.80 of the 50 s, and the 70 s scored 5.90, significantly lower than the $50 s^{\prime}$. In the case of factor 3, spatial cognitive ability, there was no significant difference until the 60s, the average scored 6.93 , whereas the 70 s scored 1.87 with significant decrease. Total VMIS-KE $(r=0.794, P<0.001)$ and all three factors $(r=$ $0.947-0.442, P<0.001)$ significantly positively correlated with MMSE (Table 5).

\section{DISCUSSION}

In this study, the first cognitive screening scale with VMI for the old people in Korea, VMIS-KE was developed and the validity and reliability of it were testified. VMIS-KE composed of 12 items, 3 subfactors, and, the KMO scale, the result of Bartlett sphericity test, and the item-total correlations were satisfied. The reliability coefficients of all factors were 0.7 or higher, the overall Cronbach alpha was 0.867 , which showed high internal consistency of the measurement, and there was no item, when deleted, with higher reliability than 0.867 , and it was judged that VMISKE was properly configured. The total cumulative explanatory variance of the three factors was $63.9 \%$, which was found to have good explanatory power. In terms of subfactors, the first factor with the highest explanatory variance of $24.8 \%$ was 'figure cognition', the second factor with the explanatory variance of $21.7 \%$ was 'memory,' and the third factor with explanatory variances of $17.4 \%$ was 'spatial cognition.'

As comparing the existing cognitive function scales with VMISKE developed in this study, there are the following differences. First, it is reduction of measurement and evaluation time through efficient questionnaire composition. Existing VMI and MMSE scales consist of seven areas, a total of 30 items, which are a relatively large number of areas and items (Folstein et al., 1975). If there are many areas or total number of items, efficiency in terms of time and cost required for measurement, evaluation, and analysis in the field decreases. VMIS-KE was minimized to 12 items and the average measurement time did not exceed $10 \mathrm{~min}$, which was to maximize feasibility and efficiency in the field.

Second, VMIS-KE is unlikely to be affected by various variables that can distort measurement results such as education, knowledge level, and experience. Currently, MMSE, which is the most commonly used to measure cognitive function in the old people, collects data through interview method, so subjective evaluation of measurer may be involved. In addition, since it focuses on language domain, it is highly likely to be affected by education level, age, and gender, and there are limitations in measuring mild cognitive impairment or evaluating visual and spatial cognitive function (Folstein et al., 1975; Kittner et al., 1986; O'Connor et al., 1989; Tombaugh and Mclntyre, 1992). On the other hand, since VMIS$\mathrm{KE}$ uses self-written questionnaires, it is possible to secure objectivity of measurement due to less subjective intervention by measurer. In addition, since the measurement method uses drawing, which is the most basic movement, it is less likely to be affected by educational level, academic ability, and intellectual ability. Therefore, VMIS-KE has the advantage that it can be used regardless of educational and intellectual level.

Third, VMIS-KE is useful as a scale to predict changes in cognitive function rather than whether or not the old people have cognitive impairment. Existing VMI tools have been used as a tool to discriminate children with disabilities or learning and behavioral problems from normal children (Cooke et al., 2004; Kooistra et al., 2005). MMSE has limitations in discriminating early mild cognitive impairment (Folstein et al., 1975). In other words, VMI or MMSE measurement tools, which are representative for measuring cognitive function, can be effective for discriminating against cognitive impairment or brain function impairment, but have limitations in evaluating and predicting normal cognitive function changes. On the other hand, the developed VMIS-KE was effective in evaluating and predicting changes in cognitive function according to age in the normal old people.

The total VMIS-KE score gradually decreased from 20s to 70s. VMI is related to appropriate self-management and academic skill performance according to the age of development and is important for observing changes in cognitive function due to various factors according to age (Feder and Majnemer, 2007). From the results of the above study, since VMI reacts sensitively with age, it can be said that it is an effective method to measure cognitive function of the old people, and VMIS-KE using this can detect cognitive function change of the normal old people than the existing tools. It can be said that it is effective in measuring and predicting.

The value of this study is to develop a prototype tool using VMI for measuring cognitive function of the Korean old people. VMIS$\mathrm{KE}$ is an effective tool that can be used conveniently in the field, regardless of level of education and knowledge of the old people, as a tool that can nonverbally measure changes in cognitive function of the old people in Korea. Through this, it is thought that it will be useful not only to detect and manage high-risk groups for dementia in the old people, but also to evaluate various cognitive 
function improvement programs. Ultimately, it is expected to contribute to reducing incidence of dementia in the old people.

In a follow-up study to develop a tool for measuring cognitive function in the old people using VMI, it is necessary to consider the following. First, standardization work using large-scale data is needed to increase the predictive power of VMIS-KE for cognitive function. Second, since there is a possibility that measurement time and environment in research process may affect result, it is necessary to standardize measurement time and environment to the most suitable for the old people. Third, VMIS-KE was an initial cognitive function scale for the Korean old people measured by VMI with arms and hands of the upper limbs corresponding to small muscles. In the future, it is necessary to develop a measurement tool that includes walking using the large lower limb muscles, which are closely related to cognitive function.

\section{CONFLICT OF INTEREST}

No potential conflict of interest relevant to this article was reported.

\section{ACKNOWLEDGMENTS}

This work was supported by the National Research Foundation of Korea Grant funded by the Korean Government (NRF-2012S1A5B6034110).

\section{REFERENCES}

Belmont I, Belmont L. Is the slow learner in the classroom learning disabled? J Learn Disabil 1980;13:496-499.

Blessed G, Tomlinson BE, Roth M. The association between quantitative measures of dementia and of senile change in the cerebral grey matter of elderly subjects. Br J Psychiatry 1968;114:797-811.

Bolk J, Padilla N, Forsman L, Broström L, Hellgren K, Åden U. Visual-motor integration and fine motor skills at $61 / 2$ years of age and associations with neonatal brain volumes in children born extremely preterm in Sweden: a population-based cohort study. BMJ Open 2018;8:e020478.

Campbell NL, Unverzagt F, LaMantia MA, Khan BA, Boustani MA. Risk factors for the progression of mild cognitive impairment to dementia. Clin Geriatr Med 2013;29:873-893.

Clemons TE, Rankin MW, McBee WL; Age-Related Eye Disease Study Research Group. Cognitive impairment in the Age-Related Eye Disease Study: AREDS report no. 16. Arch Ophthalmol 2006;124:537-543.

Cooke RW, Foulder-Hughes L, Newsham D, Clarke D. Ophthalmic im- pairment at 7 years of age in children born very preterm. Arch Dis Child Fetal Neonatal Ed 2004;89:F249-F253.

Fang Y, Wang J, Zhang Y, Qin J. The relationship of motor coordination, visual perception, and executive function to the development of 4-6-year-old Chinese preschoolers' visual motor integration skills. Biomed Res Int 2017;2017:6264254.

Feder KP, Majnemer A. Handwriting development, competency, and intervention. Dev Med Child Neurol 2007;49:312-317.

Fernández Martínez M, Castro Flores J, Pérez de Las Heras S, Mandaluniz Lekumberri A, Gordejuela Menocal M, Zarranz Imirizaldu JJ. Risk factors for dementia in the epidemiological study of Munguialde County (Basque Country-Spain). BMC Neurol 2008;8:39.

Folstein MF, Folstein SE, McHugh PR. "Mini-mental state". A practical method for grading the cognitive state of patients for the clinician. J Psychiatr Res 1975;12:189-198.

Hall S, Pinkston SL, Szalda-Petree AC, Coronis AR. The performance of healthy older adults on the Continuous Visual Memory Test and the Visual-Motor Integration Test: preliminary findings. J Clin Psychol 1996;52:449-454.

Harrabi H, Kergoat MJ, Rousseau J, Boisjoly H, Schmaltz H, Moghadaszadeh S, Roy-Gagnon MH, Freeman EE. Age-related eye disease and cognitive function. Invest Ophthalmol Vis Sci 2015;56:1217-1221.

Kittner SJ, White LR, Farmer ME, Wolz M, Kaplan E, Moes E, Brody JA, Feinleib M. Methodological issues in screening for dementia: the problem of education adjustment. J Chronic Dis 1986;39:163-170.

Knox MR, Lacritz LH, Chandler MJ, Munro Cullum C. Association between Dementia Rating Scale performance and neurocognitive domains in Alzheimer's disease. Clin Neuropsychol 2003;17:216-219.

Kooistra L, Crawford S, Dewey D, Cantell M, Kaplan BJ. Motor correlates of ADHD: contribution of reading disability and oppositional defiant disorder. J Learn Disabil 2005;38:195-206.

Lancu I, Olmer A. The minimental state examination-an up-to-date review. Harefuah 2006;145:687-690, 701.

Nelson A, Fogel BS, Faust D. Bedside cognitive screening instruments. A critical assessment. J Nerv Ment Dis 1986;174:73-83.

O'Connor DW, Pollitt PA, Treasure FP, Brook CP, Reiss BB. The influence of education, social class and sex on Mini-Mental State scores. Psychol Med 1989;19:771-776.

Pfeiffer E. A short portable mental status questionnaire for the assessment of organic brain deficit in elderly patients. J Am Geriatr Soc 1975;23: 433-441.

Shlisky J, Bloom DE, Beaudreault AR, Tucker KL, Keller HH, Freund-Levi Y, Fielding RA, Cheng FW, Jensen GL, Wu D, Meydani SN. Nutritional considerations for healthy aging and reduction in age-related chronic disease. Adv Nutr 2017;8:17-26. 
Spierer O, Fischer N, Barak A, Belkin M. Correlation between vision and cognitive function in the elderly: a cross-sectional study. Medicine (Baltimore) 2016;95:e2423.

Statistics Korea. 2020 Senior statistics [internet]. Daejeon (Korea): Statistics Korea; [cited 2021 Jun 21]. Available from: http://kostat.go.kr/portal/ korea/kor_nw/1/1/index.board?bmode=read\&aSeq=385322.
Tombaugh TN, McIntyre NJ. The mini-mental state examination: a comprehensive review. J Am Geriatr Soc 1992;40:922-935.

Yun HS, Kim E, Suh SR, Kim MH, Kim H. Diabetes reduces the cognitive function with the decrease of the visual perception and visual motor integration in male older adults. J Exerc Rehabil 2013;9:470-476. 